\title{
Los padrones de población de 1824. Espacio social y estructura socioeconómica en Lima
}

Resumen: Este artículo presenta y analiza el inconcluso padrón de población de Lima de 1824, encontrado recientemente en el Archivo Histórico Municipal de Lima, con el doble propósito de presentar su contenido y llamar la atención hacia las posibilidades historiográficas de varios corpus de información fragmentaria sobre la demografía limeña, realizados durante la temprana República. A partir del análisis de dos barrios, se realiza un acercamiento microscópico a la estructura socioeconómica de la ciudad para lograr explicar el perfil de ambos y aportar al estudio de su caracterización sociodemográfica en un periodo convulso y de continua movilidad.

Palabras clave: padrón, Lima, historia demográfica, Independencia.

\section{The 1824 census. Social space and socioeconomic structure in Lima}

Abstract: This paper shows and analyzes the unfinished 1824 population census of Lima, recently found at the Municipal Historical Archive of Lima. It has the double purpose of presenting the census' content and calling attention to the historiographic possibilities of several volumes of incomplete information on the city's demography during the early Republic. Based on the analysis of two neighborhoods, a microscopic approach to the city's socioeconomic structure is made to explain the profile of both places and contribute to studying the sociodemographic characterization of the city in a period of upheaval and continuous mobility.

Keywords: census, Lima, demographic history, Independence.

\section{Os censos de 1824. Espaço social e estrutura socioeconômica}

Resumo: Este artigo apresenta e analisa o cadastro populacional inacabado de Lima de 1824, recentemente encontrado no Arquivo Histórico Municipal de Lima, com o duplo propósito de apresentar seu conteúdo e chamar a atenção para as possibilidades historiográficas de diversos corpus de informação fragmentária para demografia limenha durante o início da República. A partir da análise de dois bairros, faz-se uma abordagem microscópica da estrutura socioeconômica da cidade a fim de explicar o perfil de ambos e contribuir para o estudo da caracterização sociodemográfica da cidade em um período de turbulência e mobilidade contínua.

Palavras-chave: censo, Lima, história demográfica, Independência.

Cómo citar este artículo: Mariana Cruz Fonseca y Enmanuel Montalvo Salcedo, "Los padrones de población de 1824. Espacio social y estructura socioeconómica”, Trashumante. Revista Americana de Historia Socia/18 [2021]: $260-291$. DOI: 10.17533/udea.trahs.n18a12

Fecha de recepción: 30 de octubre de 2020

Fecha de aprobación: 4 de marzo de 2021

Mariana Cruz Fonseca: Estudiante de pregrado en Historia en la Pontificia Universidad Católica del Perú. ORCID: 0000-0003-2423-8737.

Correo electrónico: mariana.cruz@pucp.edu.pe

Enmanuel Montalvo Salcedo: Estudiante de pregrado en Historia en la Pontificia Universidad Católica del Perú. ORCID: 0000-0001-7875-998X.

. Correo electrónico: emontalvos@pucp.edu.pe 


\title{
Los padrones de población de 1824 . Espacio social y estructura socioeconómica
}

\author{
Mariana Cruz Fonseca y Enmanuel Montalvo Salcedo
}

\section{Introducción}

El presente artículo tiene dos objetivos principales. El primero es dar a conocer Eel inconcluso padrón de población de Lima de 1824, recientemente encontrado entre los documentos del Archivo Histórico Municipal de Lima (AHML). El segundo es llamar la atención tanto de las posibilidades historiográficas que contiene el análisis del documento encontrado, como de aquellas que encierra el estudio de varios corpus de información fragmentaria sobre la demografia limeña durante los años tempranos de la República que, en medio de todo, demuestran la voluntad de las elites dirigentes de mantener los postulados liberales del gobierno tardocolonial que han sido recientemente estudiados. ${ }^{1}$ Con eso en mente, este artículo ensayará un estudio de las estructuras socioeconómicas de los barrios 1 y 3 del distrito 1 de Lima (1824), para derivar de ellas una explicación tentativa de las jerarquías socioespaciales que existían en la capital del Perú, en medio de un momento de convulsión social y franca desfragmentación de las estructuras coloniales.

Este estudio sigue el ejemplo que Linda Arnold plantea para el estudio de la jerarquización social a partir de fuentes censales en Ciudad de México, e intenta observar los "distintos y diferentes grados de acceso a bienes y servicios económicos y políticos", ${ }^{2}$ al tomar como base una unidad básica de administración de la ciudad, como es el barrio. En esa misma línea, se permite recordar lo que puede aportar el estudio diacrónico de una unidad espacial determinada, al existir varios corpus de

* Este artículo forma parte de las actividades del Grupo de investigación "Lima: espacio, sociedad y población, ss. XVIII-XIX”, del Instituto Riva Agüero, Pontificia Universidad Católica del Perú. Agradecemos a Miguel Costa Vigo y Jesús Cosamalón Aguilar por sus comentarios y apoyo constante en la presente investigación.

1. Véase, por ejemplo, el reciente estudio del Padrón de Contribuyentes de 1821. Dionisio de Haro Romero, "Para pagar la guerra: el Padrón de Contribuyentes de Lima (1821) y la política liberal del virrey La Serna”, Revista de Indias 79.275 (2019): 197-233, doi: 10.3989/revindias.2019.007.

2. Linda Arnold, "Sobre la deducción de evidencia: estratificación en un barrio de la ciudad de México, 1777-1793”, Estudios de Historia Novohispana 15 (1995): 87-111. 
información demográfica fragmentaria para el estudio de la ciudad de Lima en la temprana República, que son aún un tesoro de posibilidades no explotado.

\section{El padrón de 1824}

El periodo comprendido entre el fin del dominio colonial y el auge guanero ha sido tradicionalmente un espacio vacío para el estudio demográfico. En palabras de Paul Gootenberg, entre el último censo borbónico (1791), a cargo del virrey Gil de Taboada, y el primer censo moderno (1876), durante el gobierno de Manuel Pardo, nos encontramos con una "tierra de nadie" a nivel de información demográfica."

Autores como José Ragas, Vincent Peloso y Jesús Cosamalón Aguilar han estudiado a la población limeña del periodo previo a la Guerra del Pacífico a través del Censo de Lima de 1860. ${ }^{4}$ Más allá de la importante información demográfica que revelan, sus trabajos evidencian una tendencia diferente en el empadronamiento a inicios de la República, una que es corroborada por los informes de importantes estadísticos de la época, como Manuel Atanasio Fuentes y José María Córdova y Urrutia: la existencia y el mantenimiento de los métodos de empadronamiento locales; es decir, la redacción de periódicos censos parciales.

En ese sentido, en años recientes, las contribuciones de diversos autores han ayudado a remontar la idea del vacío demográfico de inicios de la República peruana. El mismo Gootenberg, tras estudiar los censos de 1836 y 1866 - los cuales considera pobres en resultados y métodos de realización-, presenta una nueva esperanza de data demográfica para la primera mitad de la República: el censo perdido de 1827, que se encontraría publicado parcialmente en distintos periódicos de la época. En esta misma línea, se encuentran el Padrón de Contribuyentes de 1821, así como el Padrón de Población de 1824 y el Censo Municipal realizado en 1831.

El presente trabajo coincide con Gootenberg en cuanto a que durante el proceso inmediatamente posterior a la independencia hubo un estallido de actividad censal que nunca dio como resultado publicaciones oficiales completas, por lo que ha quedado en el olvido. ${ }^{5}$ Sin embargo, la parte del producto que es visible hasta la actualidad prueba al menos dos cuestiones olvidadas: la voluntad liberal de los primeros gobiernos republicanos y el mantenimiento de las estructuras de gobierno locales, como los gobiernos locales o cabildos, a pesar de la cambiante reglamentación que por momentos abolía sus funciones o las hacía acreedoras de

3. Paul Gootenberg, Población y etnicidad en el Perú republicano (siglo XIX): algunas revisiones (Lima: Instituto de Estudios Peruanos, 1995).

4. Véase Vincent Peloso y José Ragas, "Estadística y sociedad en el Perú poscolonial: el desconocido censo de Lima de 1860", Histórica 25.2 (2001): 275-293; Jesús Cosamalón Aguilar, El juego de las apariencias. La alquimia de los mestizajes y las jerarquías sociales en Lima, siglo XIX (Lima / Ciudad de México: Instituto de Estudios Peruanos / El Colegio de México, 2017).

5. Gootenberg 19. 
un mayor número de las mismas, como recuerdan Teodoro Hampe Martínez y José F. Gálvez Montero. ${ }^{6}$

Dos instituciones permitieron que esta actividad de empadronamiento siguiera funcionando: los ayuntamientos constitucionales y la Iglesia. Así, el gobierno municipal aplicó los sistemas de empadronamiento heredados de la Iglesia tardocolonial, que en su momento habían servido para conocer a los feligreses; pero que ahora serían usados con fines distintos. ${ }^{7}$ El camino que transitaron para llegar hasta esa resolución fue accidentado. La antigua división en parroquias, que había sido utilizada por mucho tiempo por la Iglesia para administrar a los fieles y las propiedades de la orden, fue reutilizada durante el periodo de las Cortes de Cádiz para la realización de padrones de ciudadanos en 1812, una labor que se repetiría esporádicamente durante el temprano periodo republicano. Asimismo, la división urbana de la ciudad, consagrada por la "División de quarteles y barrios" (1785) y el "Nuevo reglamento de policía" (1786) dictados por el visitador Jorge Escobedo y Alarcón, sirvió - junto a sus agentes principales, los alcaldes de barrio- como el punto de inicio para el reconocimiento de una estructura de conteo rápido de la población, lo que le permitió al gobierno tener un mayor control de la misma y establecer una base para la realización del censo de 1791 y de nuevos registros fiscales para la consecución de mayores impuestos.

La Constitución de Cádiz significó otro punto de inflexión. Las leyes liberales dictaron los planes para una contribución única y general para todos los ciudadanos españoles, que incluía dentro de esa definición a blancos, mestizos e indígenas por igual.Aunque tales planes nunca se llevaron a cabo, sus ideas perduraron, como lo ha demostrado Dionisio de Haro al analizar el Padrón General de Contribuyentes de 1821, enviado a realizar por el saliente gobierno del general La Serna, el cual sentaría un precedente en la administración municipal para la elaboración de padrones republicanos. ${ }^{8}$ Es así que el conocimiento de los comisionados fiscales se superpuso sobre la vieja tradición de los alcaldes de barrio - convertidos en "comisionados" de barrio durante la etapa republicana-, lo que dio como resultado padrones que, aunque no cumplieran siempre su propósito de generar réditos al Estado, sí cumplían con dar noticia de la población enumerada.

El padrón en cuestión se realizó durante una coyuntura muy complicada. Lima había sido ocupada por los realistas entre junio y julio de 1823. Por tal razón, el presidente José de la Riva Agüero se vio obligado a trasladar su administración a Trujillo, lo que fue visto por los miembros del Congreso - quienes permanecieron en la capital - como un acto de traición, por lo que se votó su remoción del cargo el día 26 de junio y se nombró a José Bernardo Torre Tagle como jefe del gobierno. En ese momento, el Perú tenía dos gobiernos (uno en Lima y otro en Trujillo),

6. Teodoro Hampe Martínez y José F. Gálvez Montero, "De la intendencia al departamento (18101830): los cambios en la administración pública regional del Perú", Revista de Historia de América 125 (1999): 105-132.

7. Peloso y Ragas 281.

8. De Haro Romero 210. 
al general Simón Bolívar como suprema autoridad militar, al ejército movilizado y derrotado en la llamada campaña de "intermedios", y a los realistas como un bastión importante en diversas partes del país.

Así las cosas, el gobierno de Tagle decidió el 5 de enero de 1824, con asesoramiento de su ministro de Hacienda, Hipólito Unanue, la imposición de una "Capitación General sobre todo el vecindario, que no exceda de diez pesos en las personas de mejor proporción, ni baje de cuatro reales en las menesterosas". . La gestión de Tagle incluyó el mantenimiento de las prerrogativas de la municipalidad, que, según la Constitución, estaba a cargo del manejo y gobierno de la policía urbana en sus términos tradicionales. Por tal razón, fue esta institución la que ordenó la formación de "padrones exactos del vecindario de esta capital con especificación de los sexos, edades, destinos, castas y proporciones de cada uno", a cumplir en el plazo de tres días. ${ }^{10}$ Sin embargo, el plazo propuesto era imposible de cumplir, y para cuando el ejército realista volvió a capturar la ciudad en el mes de febrero, solo se habían completado dos padrones de los esperados. Cuando Bolívar entró a finales de ese año en la ciudad y se abrió la posibilidad de continuar con la labor comisionada al Cabildo, el libertador decidió acabar con la institución municipal y con los comisionados de barrio que servían a la misma, reemplazándola por un sistema militar de policía. De ese modo, la idea de una capitación general se abandonó y, al parecer, se prefirió realizar una lista de los propietarios de fincas para recolectar el impuesto. ${ }^{11}$

Un segundo objetivo fue conocer a la población que estaba en capacidad de llevar las armas y de ofrecer sus servicios en la ciudad. Así, este padrón, con una finalidad fiscal, laboral y militar, habría sido una base idónea para plantear el primer gobierno independiente del país. Su resultado es prueba de lo que se quejarían tiempo después los empadronadores: la dificultad de llevar a cabo su labor debido a la continua movilidad de la población, la desconfianza de las personas que pensaban que se les impondrían nuevos impuestos y la necesidad de recorrer amplios terrenos. $^{12}$

Aunque solo se han recuperado los registros de los barrios primero y tercero del primer cuartel, los padrones encontrados son de gran interés para conocer las características de la población limeña en un momento de alta movilidad y convulsión social.Así, por un lado, hacen posible entrecruzar variables que permiten identificar cómo estaban compuestos socialmente estos barrios, al dar noticia del tipo de habitación (vivienda), sexo, nombre, edad, destino (trabajo u oficio), casta y magnitud de propiedades de las personas consignadas en ellas. Por otro lado, posibilitan el acceso a un universo simbólico que solo se encuentra en las mentes de las personas que vivieron ese momento histórico particular y que se refleja en los criterios de los

9. Acta del 5 de enero de 1824. Archivo Histórico Municipal de Lima (AHML), Lima, Libros de Cabildo, n. 45 (1820-1824).

10. Acta del 5 de enero de 1824. AHML, Lima, Libros de Cabildo, n. 45 (1820-1824).

11. Jorge Basadre, Historia de la República del Perú (1822-1933), t. 1 (Lima: Editorial Universitaria, 1983) 145.

12. Peloso y Ragas 280. 
empadronadores, lo que constituye un aporte en el conocimiento del proceso de elaboración de esta clase de información en la temprana República.

En efecto, los comisionados de barrio que realizaron los padrones (don José Peña e Hipólito Domínguez) utilizaron variables similares, pero tuvieron un criterio particular de registro de la población. Por ejemplo, en el caso de Peña, es notorio el alto nivel de familiaridad con las personas que registra, reflejado en expresiones como "querido" o "preciado" y en el uso de diminutivos de los nombres, sobre todo de las mujeres (como "Petita"). Esta cercanía se puede explicar porque los alcaldes de barrio, por principio, vivían en los mismos barrios que empadronaban, y mantenían un mayor nivel de cercanía con la población como agentes de policía local. No obstante, las infracciones se habían vuelto comunes casi desde su inicio, como expone la situación de Hipólito Domínguez, quien no aparece en el registro del barrio que empadronó (puede tratarse de una omisión, pero lo más probable es que residiera en otro barrio), motivo por el cual el recuento producido en cada barrio va a depender mucho del celo del alcalde en cuestión. ${ }^{13}$ A pesar de que las diferencias en el registro parecieran ir en contra de las posibilidades de analizar comparativamente estas poblaciones, en realidad revelan particularidades del proceso de recolección de información, así como de la sociedad de la época, que se perderían si la atención se centra solo en los números totales.

Los barrios 1 y 3 del primer distrito poseen una estructura fisica bastante parecida, y se encontraban en la zona noroeste de la ciudad. El barrio primero se encuentra en la acera inmediatamente adyacente a la Plaza Mayor, mientras que el tercero a una distancia de una manzana hacia el sur, comprendiendo siete calles en tres manzanas hacia el oeste (Figura 1). El censo estaba destinado a conocer el número de "vecinos", es decir, el número de habitantes mayores de 16 años, por lo que en el caso del primer barrio no se consignó a los menores de edad y, en el caso del tercero, se hizo de manera sumaria, y se especificaron solo algunos casos, usualmente en los que el menor de edad estuviera involucrado en una actividad que generara réditos.

Con esto en consideración, los dos barrios registraron 947 vecinos, a quienes se sumaron 158 menores de edad del tercer barrio, para un total de 1,105 personas y 390 habitaciones; lo que significaba un 1.9\% de la población de la jurisdicción de la ciudad, incluyendo la campiña, y el 3.9\% de las habitaciones totales, al tomar como referencia el censo de $1827 .{ }^{14} \mathrm{~A}$ pesar de ser porcentualmente poco importante, el análisis de la unidad más pequeña de la administración territorial urbana, el barrio, permite un acercamiento microscópico a sus características socioeconómicas y sociodemográficas. Mediante este ejercicio se pretende conocer las características socioespaciales de estos barrios limeños, en un intento que busca determinar aspectos

13. La etapa de libertad de imprenta demostró una opinión diversa sobre los alcaldes de barrio. Véase El Investigador del Perú (Lima) 25 de octubre de 1813.

14. Gootenberg 21. 
Figura 1. Barrios 1 y 3 del distrito 1 de Lima, 1824

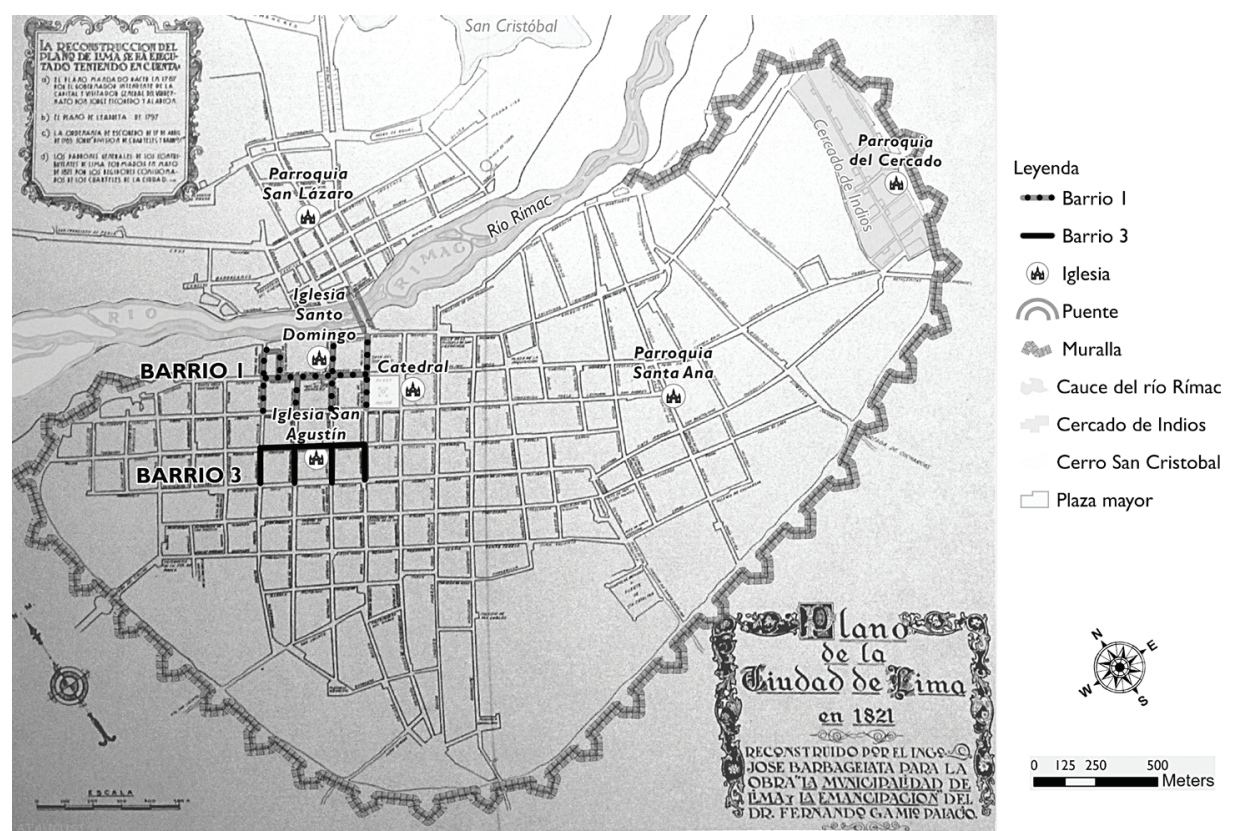

Fuente: Agradecemos a Marcos Izaguirre Liviac por la digitalización y elaboración del mapa. José Barbagelata, "Plano de la Ciudad de Lima en 1821", La municipalidad de Lima y la emancipación, 1821, Fernando Gamio Palacio (Lima: Concejo Provincial de Lima, 1944).

que de otra manera no se podrían, como, por ejemplo, los patrones de asentamiento o las relaciones intrínsecas entre variables de estratificación social.

\section{Estructura socioeconómica de dos barrios de Lima en 1824}

La ciudad de Lima había pasado, con el proceso independentista y las guerras de caudillos, por un proceso de despoblación que dejó como resultado varias propiedades y ranchos deshabitados, sobre todo en las periferias del entramado urbano. Como Gootenberg ha demostrado, el escenario limeño sufrió las consecuencias de la reducción demográfica, aunque no fue así en el campo y en determinadas regiones que permitieron que la población total peruana creciera un 22.3\% (Tabla 1).

De todas maneras, para el caso limeño ambos indicadores cayeron: la población de la capital pasó de 62,910 personas en 1791 a 58,326 en 1827. Asimismo, la Tabla 2 muestra cómo en las dos primeras décadas del siglo XIX la población del centro disminuyó en un 13\%, en comparación con el último censo de 1812, fecha en que la ciudad tuvo su pico de población antes del descenso demográfico de la primera mitad del siglo. Aunque faltan datos censales que corroboren la 
transición, el crecimiento parecería constatarse solo hacia la década de los cuarenta, con el ascenso de la economía del guano.

Aunque no hay una referencia para este dato en etapas anteriores, también se trata de un momento marcado por la ruralización y el deterioro de la ciudad. ${ }^{15} \mathrm{Si}$ en 1821 el número de propiedades era 8,222, para 1839 estas aumentaron hasta 10,605 , mas no necesariamente por un mayor número de edificaciones construidas, sino por la proliferación de pequeñas viviendas a consecuencia de la subdivisión de las antiguas casas, así como de los llamados predios inútiles o "puertas tapiadas". ${ }^{16}$ Hay que tomar en cuenta también, en esa línea, la disminución de 266 casas entre 1821 y 1839 y el cambio en el peso relativo que tendrán (de 44\% a 31\%) (Tabla 3).

Estas consideraciones generales sobre el desarrollo urbanístico de la ciudad tienen que ser explicadas en el marco de las jerarquías socioespaciales limeñas de la época. Gabriel Ramón Joffré señala cómo a fines del periodo colonial son cuatro las características que dan sentido a las jerarquías internas de la ciudad: la primera está relacionada con un mayor precio de la vara cuadrada mientras más se acercaba el terreno a la Plaza Mayor de Lima, ${ }^{17}$ lo que significaba, en la práctica, una relación más cercana con el centro de poder. La segunda es la importancia de las plazuelas como subejes dentro de la ciudad, que replicaban el funcionamiento de la principal; la tercera es la relativa a la nueva élite mercantil del siglo XVII, que habría elevado casas fastuosas en zonas más alejadas por su reciente llegada a la urbe; esta característica estaría íntimamente relacionada con la cuarta, referente a la conexión de agua privada y funcional en un escenario hídrico complicado como el limeño. ${ }^{18}$ Este patrón socioespacial habría dado como resultado una heterogeneidad social intraurbana producto tanto de la habilidad de la elite para generar nuevas formas de diferenciación, como de la subdivisión de las grandes casonas, la formación de callejones con habitaciones multifamiliares y la conquista del espacio público por la plebe urbana. ${ }^{19}$

15. Gabriel Ramón Joffré, La muralla y los callejones: intervención urbana y proyecto político en Lima durante la segunda mitad del siglo XIX (Lima: Seminario Interdisciplinario de Estudios Andinos / Comisión de Promoción del Perú, 1999).

16. No hay referencias específicas para este periodo de tiempo en datos estadísticos. El texto de José María Córdova y Urrutia es el primero en señalar el tipo de propiedades existente en Lima, al describir la existencia de 740 puertas tapiadas como un número bastante elevado. José María Córdova y Urrutia, Estadística histórica, geográfica, industrial y comercial de los pueblos que componen las provincias del departamento de Lima (Lima: Imprenta de Instrucción Primaria, 1839) 49. Manuel Atanasio Fuentes mencionará cómo la cifra descendió hasta tan solo 376 en 1857. Fuentes 653.

17. El valor aproximado de la vara cuadrada era de 0,698896 metros cuadrados.

18. Gabriel Ramón Joffré, “Autoridades subalternas y proyecto borbónico (1746-1821): el plano de las aguas urbanas de Lima”, El ocaso del antiguo régimen en los imperios ibéricos, coords. Scarlett O’Phelan Godoy y Margarita Eva Rodríguez García (Lima: Pontificia Universidad Católica del Perú / CHAM-Centro de Humanidades, Faculdade de Ciências Sociais e Humanas, Universidade Nova de Lisboa / Universidade dos Açores, 2017) 257-261.

19. Ramón Joffré, La muralla 303. 
Tabla 1. Evolución de la población de Lima en relación con el Perú, 1795-1850

\begin{tabular}{|l|c|c|c|c|}
\hline \multirow{2}{*}{ Años } & \multicolumn{2}{|c|}{ Lima } & \multicolumn{2}{c|}{ Perú } \\
\hline 1795 & Total & Índice & Total & Índice \\
\hline 1827 & 52,910 & 1 & $1 ' 239,197$ & 1 \\
\hline 1850 & 85,326 & 0.93 & $1 ' 516,693$ & 1.22 \\
\hline Fuente: Gootenberg 21: Cosamalón Aguilar, El juego 79. & & 1.35 & $2 ' 001,123$ & 1.61 \\
\hline
\end{tabular}

Tabla 2. Evolución de la población de Lima [zona urbana], 1795-1857

\begin{tabular}{|c|c|c|}
\hline Años / Lugar & Lima & [+/-] Porcentaje \\
\hline 1795 & 52,645 & - \\
\hline 1812 & 63,900 & $(+) 21.4$ \\
\hline 1839 & 55,627 & $(-) 13$ \\
\hline 1850 & 85,116 & $(+) 53$ \\
\hline 1857 & 94,195 & $(+) 10.7$ \\
\hline
\end{tabular}

Tabla 3. Número de puertas por número de casas, 1821-1839

\begin{tabular}{|c|c|c|c|c|}
\hline Tipo / Año & $\mathbf{1 8 2 1}$ & Porcentaje & $\mathbf{1 8 3 9}$ & Porcentaje \\
\hline Puertas & 8,222 & 100 & 10,605 & 100 \\
\hline Casas & 3,641 & $44.3 \%$ & 3,375 & 31.8 \\
\hline
\end{tabular}

A finales de la época virreinal, la zona en la que se ubicaban los barrios en estudio había estado dividida entre los cuarteles 1 y 2, correspondientes al área central de la ciudad de Lima y, por tanto, se ubicaban dentro centro de poder de la ciudad. Alberto Flores Galindo señala cómo en esta zona se concentraba, para fines del siglo XVIII, una importante población esclava y de relativamente pocas castas. ${ }^{20}$ 
Al seguir la diferenciación realizada por Ramón Joffré, también podemos observar cómo esta área era considerada un barrio alejado de las tuberías de cerámica (por la inclinación natural de la ciudad) y solo poseía una cañería que cruzaba ambos barrios ${ }^{21}$ lo que obligaba a la población a depender de la pileta de la Plaza Central. Para 1833, se trataba de un área con un valor de la vara cuadrada relativamente elevado (ocho pesos para el primer barrio y 6.9 pesos para el tercero).22 Además, para este mismo espacio, Cosamalón señala un cambio importante en la mitad del siglo XIX, con una mayor preponderancia de las habitaciones de alto nivel (las cuales denomina de tipo A) y la existencia de un mayor número de extranjeros y población blanca en este espacio. ${ }^{23}$ Estos datos, que serán ponderados más adelante, nos hablan de un espacio central en el escenario de Lima, asociado a los grupos y espacios de poder, el cual, no obstante, es considerado de segunda categoría y mantiene características propias del entramado urbano, como la convivencia cotidiana de personas de todas las clases y castas.

El padrón revela el número de personas que habita en cada vivienda. Siguiendo la perspectiva de Barcia Zequeira para el caso cubano, las unidades residenciales que son registradas dan cuenta de lo que tradicionalmente se denomina "familia patriarcal criolla", la cual incluía la amplia red de consanguinidad parental y la servidumbre, que cohabitaban y dormían en la misma residencia. ${ }^{24}$ Esta división necesita reconocer que muchas de las personas que vivían solas o en grandes grupos también eran parte de instituciones o del personal que residía en las tiendas; salvo en aquellos casos en que el documento revela la ocupación del único habitante, como un tendero; este es un problema dificil de notar.

Para este texto, que no se perfila como un análisis de los vínculos familiares y de parentesco existentes en el padrón, basta con señalar cómo los barrios revelan una estructura socioeconómica a partir del tipo de vivienda que se habitaba. ${ }^{25}$ Así, resalta el alto número de establecimientos comerciales (en su mayoría tiendas, pero también casas públicas, como pulperías, chinganas y cafés, que representaban un $42.2 \%$ del total), magnitud que es, además, relativamente uniforme en ambos barrios, con una ligera ventaja del barrio tercero. El segundo tipo de vivienda más

21. Según el Plan[o] Topográfico de Lima de 1787. Véase Gabriel Ramón Joffré, "Ilustrar la urbe: planos de la Lima borbónica”, Illapa 7.7 (2010): 73, doi: 10.31381/illapa.v0i7.1045.

22. Jesús Cosamalón Aguilar, Indios detrás de la muralla. Matrimonios indígenas y convivencia inter-racial en Santa Ana (Lima, 1795-1820) (Lima: Pontificia Universidad Católica del Perú, 1999) 55.

23. Cosamalón Aguilar, El juego 197.

24. María del Carmen Barcia Zequeira, "Una mirada social a las familias. Su reflejo en censos y padrones (1870-1919)", Revista de Indias 60.219 (2000): 455-456.

25. Ramón Joffré establece que, para 1836, las casonas con patios son las habitaciones de más prestigio, seguidas por las vecindades o cuartos en casas, y en tercer lugar los callejones. Ramón Joffré, La muralla 126-127. Para 1860, Cosamalón Aguilar realiza una separación de las habitaciones en tres grupos A (que incluye a las casas y casitas), B (en el que se encuentran los altos) y C (con callejones y cocheras). Cosamalón Aguilar, El juego 146. En ese sentido, ambos coinciden en colocar a las casas como la residencia más prestigiosa, estando la casita, los altos, el callejón y la cochera por debajo de ellas en orden decreciente. 
representativo es la casa, relacionada con un mayor progreso material, el cual se situaba en torno al 36.3\%. En este caso, es notorio un mayor número de casas en el barrio 1 , lo que coincide con el precio de la vara cuadrada en el área y su tradicional posición superior. El porcentaje de casitas de más bajo nivel es algo más importante en el barrio 3, con un $12.7 \%$ de los establecimientos que servían de vivienda. Finalmente, la importancia relativa que en el barrio 1 tienen los callejones, la tienen las cocheras en el barrio 3; mientras que los altos se presentan en torno al 4\% o 5\% en ambos barrios.

Tras conocer la estructura de vivienda de los barrios, es importante señalar que en el $45.3 \%$ de ellas habitaban entre dos y cinco personas, lo que correspondería en los esquemas clásicos a un sistema de familia nuclear, tendencia que se vería confirmada por el $41.6 \%$ de habitaciones simples y solo un $13.2 \%$ con más de seis personas. El promedio de personas por habitación era superior en el barrio 3, el más poblado de los dos; esto se encuentra relacionado a un mayor porcentaje relativo de personas en habitaciones de más de seis personas (19\% contra $7.4 \%$ del barrio 1$)$.

La cuestión se vuelve más clara al revisar cuántas personas residían en cada tipo de habitación. De esta forma, se observa cómo las casas eran el espacio de habitación preferido en ambos barrios (46.9\% y 54.6\%), mientras que el segundo lugar lo ocuparon los establecimientos comerciales $(23.4 \%$ y $23.9 \%)$. Es a partir de aquí que se produce una diferencia más grande, pues casi un 20\% habitaba los callejones del barrio 1, mientras que solo un 2.9\% lo hacía en el barrio 3 . En ese sentido, el tercer puesto de espacios de habitación preferido lo tenían, para el barrio 3, las casitas. Todo parece indicar que la estructura del barrio 1 era más abigarrada (tal vez por incluir el Convento de Santo Domingo y tomar en cuenta las calles que dan hacia el río) que la del barrio 3, por lo que los estratos populares de este barrio no habitaban los callejones, sino las casitas y los altos. ${ }^{26}$

Un elemento más importante se deduce al observar el promedio desagregado de personas por habitación. En el caso de los callejones, el promedio bajó bastante en el barrio 3, aunque es compensado por el aumento en las personas que habitaban los altos. El dato del promedio de personas por casita (casi el doble en el barrio 3) confirma la tendencia del barrio de ocupar los altos y las casitas, en lugar de los callejones, como espacios de vivienda popular. Lo que más llama la atención es el alto número de personas por cada casa del barrio 3 (7.5), sobre todo en comparación con el barrio 1, que solo asciende a 2.4 en promedio, a pesar de ser el tipo de vivienda más utilizada del área. Por las circunstancias del momento, empieza a haber señales de empobrecimiento en el barrio 1, lo que se podría inferir de la relativa despoblación de sus casas.

Es posible observar más detalles sobre la población a través de la estructura de sexo y edad de los barrios; no obstante, cada barrio tiene particularidades en la forma de registrar estas variables. El padrón del primer barrio, por ejemplo, solo cuenta

26. Algo que coincide con la realidad estudiada del devenir arquitectónico de la época; por ejemplo, el callejón de la Toma de Santo Domingo, ubicado en el barrio primero y antiguamente parte del Convento de la misma orden. 
Tabla 4. Estructura de vivienda. Barrios 1 y 3, 1824

\begin{tabular}{|l|c|c|c|c|c|c|}
\hline $\begin{array}{l}\text { Tipo de } \\
\text { habitación }\end{array}$ & B1 & Porcentaje & B3 & Porcentaje & Total & Porcentaje \\
\hline Casa & 76 & 46.9 & 40 & 25.3 & 116 & 36.3 \\
\hline Casita & 6 & 3.7 & 20 & 12.7 & 26 & 8.1 \\
\hline Cochera & {$[2]$} & - & 8 & 5.1 & 8 & 2.5 \\
\hline Altos & 8 & 4.9 & 6 & 3.8 & 14 & 4.4 \\
\hline Callejón & 9 & 5.6 & 3 & 1.9 & 12 & 3.8 \\
\hline $\begin{array}{l}\text { Establecimientos } \\
\text { comerciales }\end{array}$ & 61 & 37.7 & 74 & 46.8 & 135 & 42.2 \\
\hline No confirmado & 2 & 1.2 & 7 & 4.4 & 9 & 2.8 \\
\hline Total & 162 & 100 & 158 & 100 & 320 & 100 \\
\hline Fuente: AHML, Lima, Gobiernos Distritales 1812-1839. Censo general del barrio 1y padrón del barrio 3, 1824. & & \\
\hline
\end{tabular}

Tabla 5. Número de personas por habitación. Barrios 1 y 3, 1824

\begin{tabular}{|c|c|c|c|c|c|c|}
\hline $\begin{array}{l}\text { Número de } \\
\text { personas }\end{array}$ & B1 & Porcentaje & B3 & Porcentaje & Total & Porcentaje \\
\hline 1 & 79 & 48.8 & 54 & 34.2 & 133 & 41.6 \\
\hline $2-5$ & 71 & 43.8 & 74 & 46.8 & 145 & 45.3 \\
\hline $6-10$ & 7 & 4.3 & 21 & 13.3 & 28 & 8.8 \\
\hline más de 11 & 5 & 3.1 & 9 & 5.7 & 14 & 4.4 \\
\hline $\begin{array}{l}\text { Total de } \\
\text { habitaciones }\end{array}$ & 162 & 100 & 158 & 100 & 320 & 100 \\
\hline Total personas & 384 & & 563 & & 1,029 & \\
\hline $\begin{array}{l}\text { Promedio de } \\
\text { personas por } \\
\text { habitación }\end{array}$ & 2.4 & & 3.6 & & 3.2 & \\
\hline \multicolumn{7}{|c|}{$\begin{array}{l}\text { Nota: Para poder comparar ambos barrios, no se ha tomado en cuenta a los menores de } \\
\text { edad, únicamente consignados en el barrio tres. }\end{array}$} \\
\hline \multicolumn{7}{|c|}{ Fuente: AHML, Lima, Gobiernos Distritales 1812-1839, Padrón de población de Lima, 1824.} \\
\hline
\end{tabular}


Tabla 6. Número de personas por barrio según tipo de vivienda. Barrios 1 y 3, 1824

\begin{tabular}{|l|c|c|c|c|c|c|}
\hline Tipo de habitación & B1 & Porcentaje & Promedio & B3 & Porcentaje & Promedio \\
\hline Casa & 180 & 46.9 & 2.4 & 299 & 53.1 & 7.5 \\
\hline Casita & 10 & 2.9 & 1.7 & 58 & 10.3 & 2.9 \\
\hline Cochera & 3 & 0.8 & 1.5 & 11 & 2 & 1.4 \\
\hline Altos & 23 & 6 & 2.9 & 29 & 5.2 & 5.2 \\
\hline Callejón & 76 & 19.8 & 8.4 & 17 & 3 & 3 \\
\hline $\begin{array}{l}\text { Establecimientos } \\
\text { comerciales }\end{array}$ & 90 & 23.4 & 1.5 & 135 & 24 & 2.5 \\
\hline No confirmado & 2 & 0.5 & 1 & 14 & 2.2 & 2 \\
\hline Total & 384 & 100 & & 563 & 100 & \\
\hline
\end{tabular}

a tres mujeres en el rango de 0 a 15 años, pues excluye a la población menor de edad. De la misma forma, el del tercer barrio, si bien cuenta con nombres y apellidos a 82 jóvenes y niños en ese rango de edad, menciona a otro grupo de 76 "hijos chiquitos" sin diferenciar su sexo. Por tales razones, se ha decidido pasar al análisis de las pirámides poblaciones excluyendo momentáneamente a la población infantil. Con esa salvedad, lo primero que salta la vista es la gran diferencia en el grupo de edad de 16 a 30 años, años fértiles y de mayor producción laboral, en el que hay un fuerte desbalance de sexos a favor de las mujeres $(64.9 \%$ contra un $35.1 \%$, es decir, casi 30\% más). La diferencia tan amplia entre hombres y mujeres en este grupo se debe a la misma naturaleza militar y laboral del padrón (que excluye, como hemos visto, a los infantes), así como al convulso momento en que este se realizó, con una gran población masculina movilizada para la guerra.

Como se mencionó previamente, la población limeña de 1823 y 1824 se encontraba en un momento de alta movilidad, la cual, según Massimo Livi-Bacci, es propia de una sociedad con alta fragmentación, hasta en sus dimensiones más pequeñas, $y$, a diferencia de una población estable, su estructura de edad se ve influenciada por factores externos y no por niveles normales de fertilidad y mortalidad. ${ }^{27}$ En otras palabras, las guerras de independencia alteraron, como un factor externo, la estructura de edad de la capital peruana, debido al notorio desplazamiento de varones a las filas de los ejércitos. La tendencia no cambia en el desagregado de los barrios; de hecho, se vuelve aún más pronunciada en el caso del barrio 3, a pesar de ser el que contiene mayor población de los dos. Indias 76.267 (2016): 419-448, doi: 10.3989/revindias.2016.013. 
El desagregado de la población infantil para el barrio 3 permite observar que esta representaba el 21.9\% del barrio. Asimismo, se observa el sesgo del documento a favor de la población en edad laboral (42\% del total); los resultados generales son claros al mostrar una población joven con preeminencia de la población en edad laboral. Asimismo, presenta una alta feminización debido a la coyuntura bélica del proceso independentista, así como una alta tasa de mujeres en la servidumbre doméstica. Por lo demás, los otros grupos quincenales parecen mantener un relativo balance entre los sexos, salvo por la población mayor de 60 años, que son en su mayoría hombres $(66.2 \%$ contra 33.8\%). La pirámide poblacional es propia de un espacio social que sirve de habitación para muchos jóvenes en edad laboral y de matrimonio; el número de hombres en esta etapa se encontraría disminuido por el subregistro, asociado a los propósitos impositivos y militares del padrón. Así, la situación bélica explicaría la gran diferencia porcentual a favor de las mujeres, que pueden haber quedado a cargo de las casas, manteniendo a la familia mediante el trabajo a domicilio o en el servicio doméstico.

Para arrojar luces sobre esta hipótesis, se debe pasar al análisis de las ocupaciones consignadas en el documento. Al contrario de las limitaciones clásicas de las numeraciones hechas durante el siglo XIX, este documento, al haber sido hecho con el objetivo de conocer a la población en edad capacidad de contribuir económicamente, ha consignado la ocupación de un 69.9\% del total de las personas en edad laboral (663 de 947 mayores de 15 años). Es sobre todo el padrón del barrio 3 el que mantiene esta alta tasa de registro (87.6\%), mientras que el del barrio 1 mantiene el tradicional problema de este tipo de fuentes, con un subregistro del $56 \%$. Lo que corrobora la factibilidad de la información dada por el comisario del barrio 3, don José Peña, es que señala explícitamente que muchas personas no tienen actividad conocida, y así lo consigna en la categoría "ninguno" (164 registros). No es la única particularidad de este comisario, quien además menciona la existencia de 21 jóvenes menores de 15 años trabajadores. Así, el número total de personas que trabajan en el barrio 3 es de 350 personas, es decir, $48.5 \%$ del total de personas en edad de trabajar. En relación con la tasa de trabajo en general, queda decir que 519 personas (169 del barrio 1 y 350 del barrio 3) fueron consignadas con algún tipo de ocupación.

Tabla 7. Población en edad laboral y nivel de registro por barrio. Barrios 1 y 3, 1824

\begin{tabular}{|l|c|c|c|c|c|c|}
\hline & B1 & Porcentaje & B3 & Porcentaje & Total & Porcentaje \\
\hline Registrada & 169 & 44 & 493 & 87.6 & 662 & 69.9 \\
\hline No registrada & 215 & 56 & 70 & 12.4 & 285 & 30.1 \\
\hline $\begin{array}{l}\text { Población en } \\
\text { edad laboral }\end{array}$ & 384 & & 563 & & 947 & \\
\hline
\end{tabular}


Figura 2. Estructura de sexo y edad. Barrios 1 y 3,1824

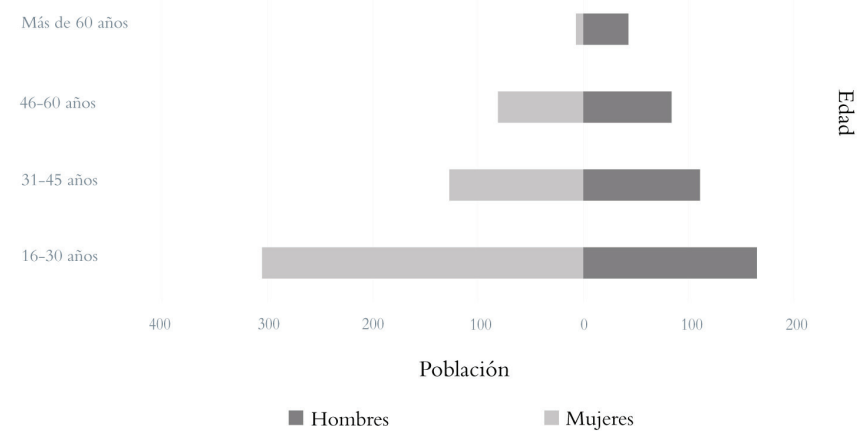

Fuente: AHML, Gobiernos Distritales 1812-1839, Padrón de población de Lima, 1824.

Figura 3. Estructura de sexo y edad. Barrio 1, 1824
Más de 60 años
$46-60$ años
31-45 años
16-30 años

150

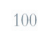

Población

\section{$\frac{\text { Th1 }}{\stackrel{2}{2}}$}

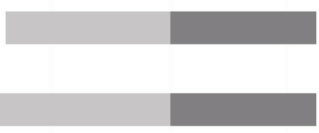

$50 \quad 100$

100

Mujeres

Fuente: AHML, Gobiernos Distritales 1812-1839, Padrón de población de Lima, 1824.

Figura 4. Estructura de sexo y edad. Barrio 3, 1824

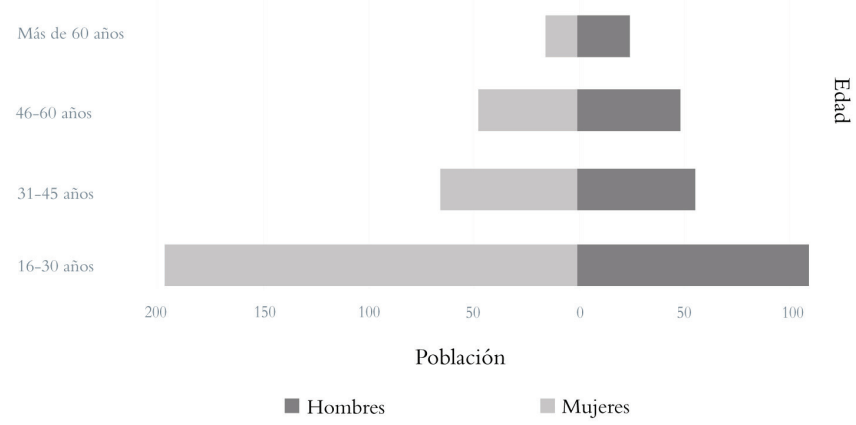

Fuente: AHML, Gobiernos Distritales 1812-1839, Padrón de población de Lima, 1824. 
El tema del trabajo femenino es un apartado interesante que se puede dilucidar a través de este padrón. Nuevamente el barrio 1 tiene un número mayor de subregistro, al consignar el dato solo para el 17.2\% de las mujeres que trabajan, mientras que el barrio 3 menciona el caso solo para un 35.3\%. Con todo, la información proporcionada, particularmente en este último caso, es reveladora. El grupo más grande era el de las trabajadoras domésticas, quienes se veían vinculadas al servicio al interior de las casas de familias (como sirvientas y cocineras), así como a los servicios vinculados al ámbito doméstico, como lavar ropa. En general, el alto número de mujeres dedicadas a labores del hogar habla de una población que habita en casas de familia y pueden solventar el gasto que este servicio implica.

El siguiente grupo eran las artesanas (30\%). Esto se explica por la importancia de las mujeres que laboraban a domicilio sin salir de sus casas, como costureras (43 registros), posición que les permitía ganar un jornal sin alterar su prestigio y mantener su honor intacto.28 Un número mucho menor se dedicaba a otros trabajos artesanales, principalmente como cigarreras. En efecto, las mujeres también se dedicaron a oficios en la esfera pública, aunque en menor proporción. Entre ellas se encontraban fundamentalmente las chinganeras, las placeras, las fruteras y las recauderas, entre otras actividades que se encuentran bajo el rubro de tenderos (19.2\%); asimismo, había tres cómicas, una boticaria profesional y un número pequeño de otros oficios que no han podido ser identificados. De esta forma, el número de trabajadoras (172) es importante entre la población de jóvenes limeños, lo que nos indica la necesidad de buscar empleo por parte de ambos sexos, agudizada por el contexto de crisis generalizada.

Tabla 8. Estructura general de trabajadores domésticos. Barrios 1 y 3, 1824

\begin{tabular}{|c|c|c|c|c|c|c|}
\hline & Mozo & Mayordomo & Cocinero/a & Sirviente/a & Lavandera & Total \\
\hline F & & & 4 & 39 & 21 & 64 \\
\hline M & 4 & 4 & 4 & 37 & \\
\hline
\end{tabular}

En proporción, la mayor categoría era la de los artesanos (33.5\%), debido al alto número de costureras, quienes conformaban el grupo más grande, seguidas por los sastres, zapateros y plateros. Luego venían las personas dedicadas a la construcción, como los pintores, carpinteros, silleros, entre otros, y un último número importante lo constituían las y los cigarreros. Finalmente, se hallaban en pequeños números los armeros, bordadores, hojalateros, herreros, sombrereros, un curtidor, un albañil, un tornero y un botonero. Es importante señalar que los artesanos dedicados a la

28. Margarita Zegarra Flórez, "El honesto velo de nuestro sexo. Sociabilidad y género en mujeres de sectores populares en la Lima del 800", Mujeres y Género en la Historia del Perú, ed. Margarita Zegarra Flórez (Lima: CENDOC - Mujer, 1999) 193-195. 
confección de ropa (desde el humilde botonero hasta el significativo número de sastres) representaban el $55.2 \%$ de los oficios artesanales. Al ser el número de trabajadores domésticos mucho menor en el barrio 1, estos oficios ocupaban allí el mayor peso relativo $(32.5 \%)$.

El segundo grupo en importancia eran los trabajadores domésticos, donde las mujeres, como se ha señalado previamente, representaban la mayoría, al ser el $56.6 \%$ de todos los trabajadores del hogar. Para los varones, el trabajo doméstico también fue importante; ellos se desempeñaban como cocineros y en labores de servicio de mayor importancia social, como mozos y mayordomos. Finalmente, participaban en proporción casi idéntica a las mujeres como sirvientes plenos (37 de 76 sirvientes, lo que representa el $48.7 \%$ del grupo). También se evidencia que el barrio 3 mantuvo una población doméstica mucho más grande, que concentraba al 100\% de los sirvientes plenos, mientras que el barrio 1 aportaba un número reducido de cocineras y lavanderas. Esto probablemente señale un empobrecimiento relativo del barrio. En ese sentido, el hecho de que los servicios menores y el trabajo doméstico se vieran disminuidos a un segundo lugar en una urbe con tradición de basarse en tales actividades puede expresar un momento excepcional de búsqueda de trabajo en distintas esferas y en el que el tradicional grupo rentista que proporcionaba esta posibilidad de empleo se vio disminuido por los trastoques de la lucha independentista. ${ }^{29}$

Los siguientes en importancia fueron los tenderos (13.5\%), quienes trabajaban expidiendo alimentos y otros productos básicos, o en la atención a la clientela. Se trataba de recauderos, cajoneros, chinganeros, pulperos, fruteras, fresqueras, fonderos, chicheros, algún posadero, un pastelero y un cafetero. El similar peso relativo en ambos barrios habla de la necesidad de surtirse de productos básicos que había en ambas zonas y de las oportunidades que este negocio brindaba para momentos de crisis como este. A los tenderos les seguían los comerciantes, quienes estaban compuestos por 25 extranjeros y 21 peruanos. Aunque este dato no se menciona de forma sistemática en ambos padrones, razón por la cual no se ha estudiado de forma separada, si se consigna para el caso de los comerciantes (quienes eran extranjeros en un $54.3 \%$ de los casos). Así, es posible conocer que los barrios estudiados eran un espacio que acogía a los comerciantes, ya fuera en casas de alquiler o bajo la tutela de alguna familia local.

Posteriormente, estaban los profesionales educados (eclesiásticos, burócratas y abogados), quienes sumaban un 6\%; luego los militares de diverso rango, con un $4.6 \%$ (sobre ellos, se asume que servían como milicia local o guardias). Hay un número que registra otras profesiones (3.3\%), las cuales incluyen barberos, serenos, un aguador, un colgador, un granjero y al menos cuatro personas sin oficio conocido, pero que no son consignadas como tal, sino bajo el nombre

29. Cosamalón Aguilar hace alusión a esa primacía histórica de los servicios en Lima durante el siglo XIX. Cosamalón Aguilar, El juego 193-194. 
de emigradas, transeúntes o "vagos jugadores", lo que puede aludir a la movilización que significó la coyuntura bélica. Asimismo, hay un pequeño rubro de artistas cómicos de ambos sexos (1\%), dedicados al entretenimiento. Por último, el número de personas con ocupación no identificada suma un 2.7\%. Mención aparte merecen los jóvenes, cuyas ocupaciones se dividían en: nueve sirvientes, cinco aprendices artesanales, tres dependientes de comercio, un estudiante, un "boticario" - quien probablemente ayudaba a su padre en esa labor-, una placera y una doncella.

Figura 5. Estructura de trabajo femenino. Barrios 1 y 3, 1824

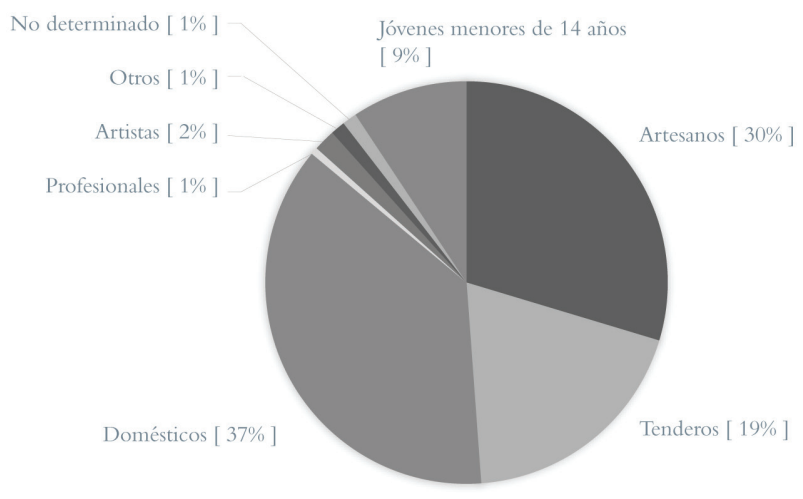

Fuente:AHML, Gobiernos Distritales 1812-1839, Padrón de población de Lima, 1824.

Figura 6. Composición étnica de Lima, 1827

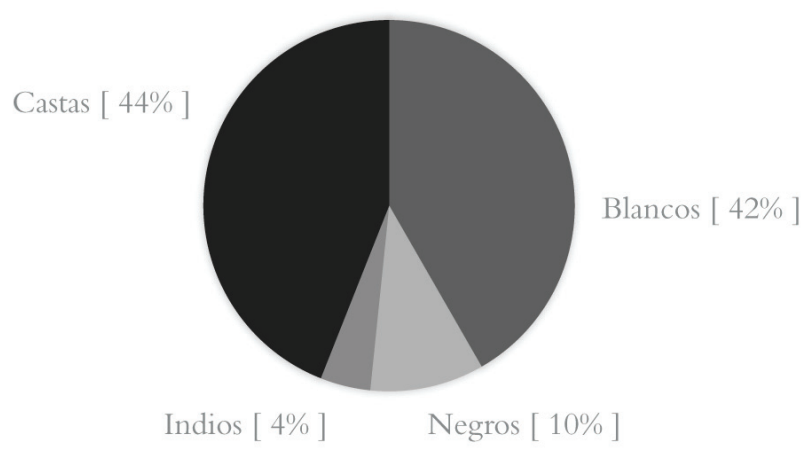

Fuente: Gootenberg 21; Cosamalón Aguilar, El juego 93 


\section{3. “Casta” y "calidad” en Lima, 1824}

La estructura de ocupaciones de los barrios 1 y 3 arroja luces sobre cuál era la estructura socioeconómica de la población residente, pero es la variable casta/ calidad la que más decididamente otorga una perspectiva acerca de cuáles eran las jerarquías internas dentro de estos barrios (y la ciudad). No obstante, ¿qué se debe entender por "casta" en estos padrones?

La sociedad colonial había planteado un régimen de repúblicas separadas que comenzó a romperse casi de inmediato en el siglo XVI. Tradicionalmente, se ha hablado del mestizaje biológico para explicar este proceso de integración, sin embargo, autores como Tadashi Obara-Saeki señalan cómo la clasificación social que construye este proceso no tiene carácter científico y se basó más en la perspectiva del grupo dominante que en el mestizaje genético, razón por la cual prefiere hablar de exogamia o "relaciones sociohistóricas que existían entre indios, españoles, negros, mestizos, mulatos, etcétera" $\cdot{ }^{30}$ Así las cosas, rápidamente el rótulo de "mestizo" dejó de ser lo que inicialmente definió el término (es decir, una "mezcla" entre indio y español), y comenzó a referirse al hecho de que la persona era una "mezcla" en sí misma, denominación que se valió de factores económicos y estamentales. En ese sentido, la importancia tradicional que se le ha dado al factor raza (entendida como factor biológico) es exagerada. El término "casta", que originalmente se refiere al linaje o la procedencia de algo, estaba ya - a fines del periodo colonial - muy imbricado con el concepto de "calidad", que se relaciona con la "cualidad" de las personas e incluye factores económicos y sociales. ${ }^{31}$ Verena Stolcke, en su estudio al respecto, ha señalado cómo estos nuevos elementos eran vistos en la sociedad colonial desde el lente del pigmento. ${ }^{32}$ Así, los términos "casta" o "calidad" funcionaban como "elementos que sintetizaban la condición de las personas (...) pertenecer o no a un grupo racial determinado era el producto de un conjunto de factores, tales como la vestimenta, el estatus económico, el origen de los padres, la complacencia o indiferencia del cura o funcionario que registraba y la percepción social." ${ }_{33}$

Entonces, la definición del término casta/calidad estaba íntimamente relacionada con la capacidad de los empadronadores para observarla, por lo que cabe examinar las diferencias en la forma de registro en ambos barrios. En el barrio 1, se

30. Tadashi Obara-Saeki, Ladinización sin mestizaje. Historia demográfica del área chiapaneca, 1748-1813 (Chiapas: Consejo Estatal para las Culturas y Artes de Chiapas, 2010) 25-33.

31. Alejandra Araya Espinoza, "Registrar a la plebe o el color de las castas: 'calidad', 'clase' y 'casta' en la Matrícula de Alday (Chile, siglo XVIII)", América colonial. Denominaciones, clasificaciones e identidades, Chile, siglo XVIII, eds. Alejandra Araya Espinoza y Jaime Valenzuela Márquez (Santiago de Chile: RIL Editores / Pontificia Universidad Católica de Chile / Universidad de Chile, 2010) 346-347.

32. Verena Stolcke, Racismo y sexualidad en la Cuba colonial (Madrid: Alianza Editorial, 1992) 205.

33. Cosamalón Aguilar, El juego 26. Esta discusión nace del clásico texto deVerena Stolcke sobre el tema, que afirma que "la posición racial del individuo no se deriva de cada factor independientemente uno de otro, sino de que estaba determinada por la combinación de todos ellos”. Stolcke 205. 
consignó la información de calidad para el $86.5 \%$ de los casos, mientras que en el barrio 3 se posee el dato para un $88.5 \%$, y, lo que es más esclarecedor: si se excluye a los "76 niños chiquitos", cuyo dato de casta no se consigna, se tiene el dato para un $98.8 \%$ de la población empadronada (Tabla 9). La recolección de información sumaria en el caso del primer barrio tuvo que atenerse al poco tiempo y a las dificiles condiciones en que se hizo el padrón, así como al desconocimiento del barrio por parte del comisionado, por lo que la caracterización fenotípica le permitió hacer una clasificación general al empadronador. En cambio, en el caso del barrio 3, el comisionado don José Peña demostró una mayor cercanía con sus vecinos al dar una detallada clasificación de los habitantes según casta, con términos como "cuarterón", "requinterón", etcétera. ${ }^{34}$ Para realizar esta diferenciación específica se necesitaba no solo el conocimiento de las taxonomías sociales de fines de la colonia, sino que también requería que se conociera la ascendencia de la persona para colocarla en determinada casta. Esta realidad ejemplifica lo que señala David Parker, aunque para un distinto espacio temporal, acerca de que la pertenencia social a determinado grupo "no radicaba en cómo el individuo se autoidentificaba, sino en cómo era identificado por los demás". 35

Sin embargo, lo que es evidente de la designación por castas es que la mayoría de la población en estos barrios es considerada "blanca" (59.1\%), mientras el segundo grupo representativo lo conforman las diversas castas (20.5\%), así como un número de peruanos ${ }^{36}$ y negros minoritarios (7.9\% y $6.7 \%$, respectivamente). La tendencia se relaciona con los valores totales del censo de 1827, presentados en la Figura 6, en el que $41.7 \%$ de la población fue considerada "blanca", mientras que la mayoría de la población pertenecía a las castas (44\%) y un reducido número a los indios y negros. La postura de Cosamalón era acertada al señalar esta realidad como parte del llamado proceso de "blanqueamiento", en el que los negros e indígenas progresivamente iban integrándose en los resquicios del sistema, engrosando el número de las castas y algunos pocos llegaron al rótulo de "blanco". ${ }^{37}$ Con todo, este barrio parecía especialmente poblado por este último grupo, si se toma en cuenta el total del censo. Se volverá a este punto más adelante.

34. A fines del siglo XVIII se creó toda una taxonomía de las mezclas "raciales" en el Perú.Véase Juan Carlos Estenssoro Fuchs y otros, "Los colores de la plebe: razón y mestizaje en el Perú colonial", Los cuadros de mestizaje del virrey Amat: la representación etnográfica en el Perú colonial, ed. Natalia Majluf (Lima: Museo de Arte de Lima, 1999).

35. David S. Parker, "Los pobres de clase media: estilo de vida, consumo e identidad en una ciudad tradicional", Mundos Interiores: Lima 1850-1950, eds. Aldo Panfichi H. y Felipe Portocarrero S. (Lima: Universidad del Pacífico, 1995) 165.

36. José de San Martín decretó a los pocos días de la Independencia que ya no se llamaría "naturales" ni "indios" a los habitantes originarios del país, sino que adoptarían el nombre de "peruanos" por ser ellos ciudadanos del Perú. Maud Yvinec, "Reinventar el indio después de la Independencia: las representaciones del indígena en el Perú decimonónico (1821-1879)", Bulletin de l'Institut Français d'Études Andines 42.2 (2013): 287-293, doi: 10.4000/bifea.4087.

37. Cosamalón Aguilar, El juego 94-95. 
Tabla 9. Distribución de la población trabajadora según tipo de oficios y barrio. Barrios 1 y 3, 1824

\begin{tabular}{|l|c|c|c|c|c|c|}
\hline \multicolumn{1}{|c|}{ Oficios } & B1 & Porcentaje & B3 & Porcentaje & Total & Porcentaje \\
\hline Comerciantes & 24 & 14.2 & 22 & 6.3 & 46 & 8.9 \\
\hline Artesanos & 55 & 32.5 & 119 & 21.7 & 174 & 33.5 \\
\hline Tenderos & 32 & 18.9 & 38 & 10.9 & 70 & 13.5 \\
\hline Domésticos & 17 & 10.1 & 87 & 37.1 & 147 & 20 \\
\hline Militares & 7 & 4.1 & 17 & 4.9 & 24 & 4.6 \\
\hline Profesionales & 10 & 5.9 & 21 & 6 & 31 & 6 \\
\hline Empleados/as & 7 & 4.1 & 4 & 1.1 & 11 & 2.1 \\
\hline Artistas & 1 & 0.6 & 4 & 1.1 & 5 & 1 \\
\hline Otros & 12 & 7.1 & 5 & 1.4 & 17 & 3.3 \\
\hline Menores de 14 años & - & - & 21 & 6 & 21 & 4 \\
\hline No determinado & 2 & 1.2 & 12 & 3.4 & 14 & 2.7 \\
\hline
\end{tabular}

Tabla 10. Composición étnica de los barrios 1 y 3, 1824

\begin{tabular}{|l|c|c|c|c|c|c|}
\hline \multicolumn{1}{|c|}{ Casta } & B1 & Porcentaje & B3 & Porcentaje & Total & Porcentaje \\
\hline Blancos & 218 & 56.8 & 391 & 60.5 & 609 & 59.1 \\
\hline Peruanos & 11 & 2.9 & 70 & 10.8 & 81 & 7.9 \\
\hline Negros & 11 & 2.9 & 58 & 9 & 69 & 6.7 \\
\hline Castas & 92 & 24 & 119 & 18.4 & 211 & 20.5 \\
\hline Sin dato & 52 & 13.5 & 8 & 1.2 & 60 & 5.8 \\
\hline Total & 384 & 100 & 646 & 100 & 1,030 & 100 \\
\hline
\end{tabular}


Con las consideraciones previas, parece evidente que usar solo la casta como variable para entender la jerarquización social de la población es insuficiente; debido a ello, este texto toma como punto de partida las consideraciones de Linda Arnold sobre el particular. Para la autora, existen otros factores que serían claves para entender esta compleja realidad, como la ocupación, el tipo de unidad residencial, la presencia explícita o implícita de servidores domésticos y la posibilidad de ostentar el título de "don" o "doña", como símbolo de estatus social. ${ }^{38}$ En efecto, un título o una relación económica vigente (como la servidumbre) puede dilucidar el contexto socioeconómico de la persona de una mejor manera que lo hace su lugar de procedencia.

En ese sentido, podemos observar cómo la población blanca predominaba en las actividades mercantiles y profesionales por una abrumadora mayoría, que sería mayor en el caso de las profesionales, de no ser por un registro no determinado de calidad más o menos relevante (7.4\%). También constituyeron el total de las y los cómicos consignados en el rubro de artistas, y son eran mayoría calificada entre los empleados y los militares, aunque en este aspecto las castas alcanzaron una representación significativa (18.2\% y $10.7 \%$, respectivamente).

Aunque las castas, peruanos y negros (es decir, grupos no blancos) no constituyeron por separado la mayoría en ninguno de los rubros laborales, el acumulado de estos grupos juntos conformó la mayor parte de artesanos, domésticos y tenderos. Esto merece ser explicado con más detalle. En cuanto a los artesanos (Figura 8), las castas se encontraban en todo el espectro de oficios. Algo parecido sucedía con los blancos, aunque llegaban a constituir mayoría en tres rubros: cigarreros, plateros y en el de las mujeres costureras, las cuales podían conservar su honor de esta manera; por tal razón, se convirtieron en las labores preferidas de las mujeres blancas en situación de necesidad. Esta última situación resultaba muy dificil para las mujeres afrodescendientes e indígenas, quienes tenían que salir a la calle a trabajar, así como servir de lavanderas o sirvientas, oficios de menor prestigio social.

En efecto, la estructura del trabajo doméstico también fue distinta según la calidad, pues las castas y los negros constituían el 56.5\% de las personas del rubro (Figura 9). Como ya se había visto, quienes se desempeñaban en las labores domésticas de mayor prestigio, como mozos y mayordomos, eran varones, y ahora se sabe que estos eran blancos. Finalmente, la Figura 8 también permite observar que el grupo donde estaban mejor representados los "negros" — epíteto que fue desapareciendo a favor de "castas" en el transcurso del siglo - es el de sirvientes, lo que hace sospechar que los esclavos recién declarados libres mantuvieron su trabajo como sirvientes domésticos.

Finalmente, los tenderos, dedicados al rubro de los alimentos, también eran en su mayoría no blancos. Existía una clara división entre los tenderos blancos (cafeteros, fonderos, posaderos, pulperos y chinganeros) y los no blancos (chicheros, fresqueros, fruteros, recauderas y placeras), que era la posesión de un local o casa pública para la venta. En algunas actividades de venta informal o al aire libre también incursionaban 
Figura 7. Estructura de oficios según calidad. Barrios 1 y 3,1824

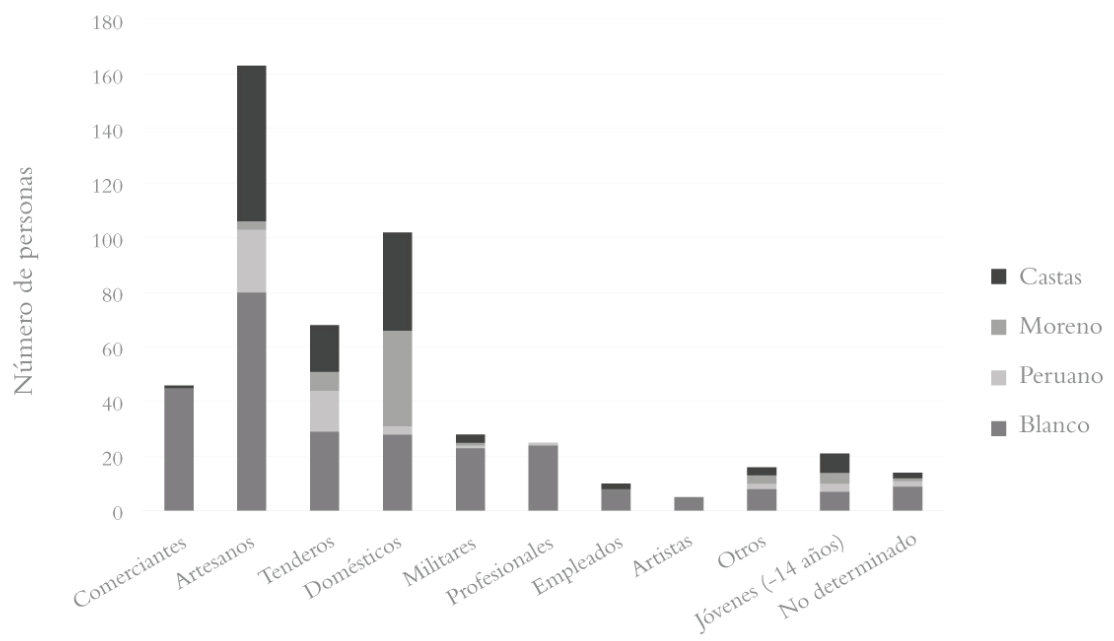

Fuente: AHML, Gobiernos Distritales 1812-1839, Padrón de población de Lima, 1824.

Figura 8. Estructura de artesanos según casta [cinco datos mayores]

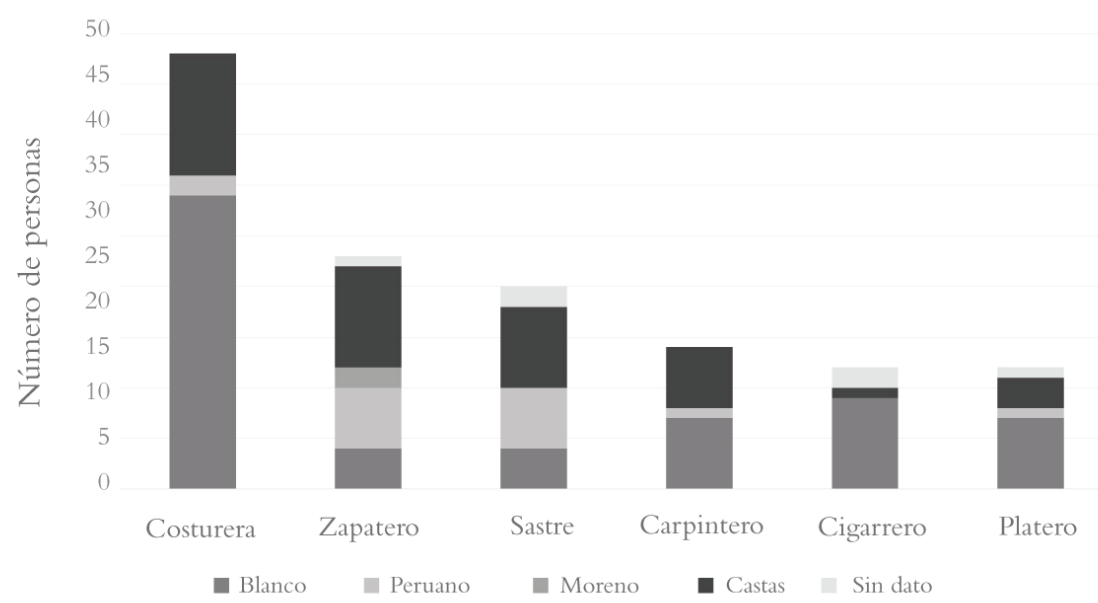

Fuente: AHML, Gobiernos Distritales 1812-1839, Padrón de población de Lima, 1824. 
Figura 9. Estructura de sirvientes domésticos según casta. Barrios 1 y 3, 1824

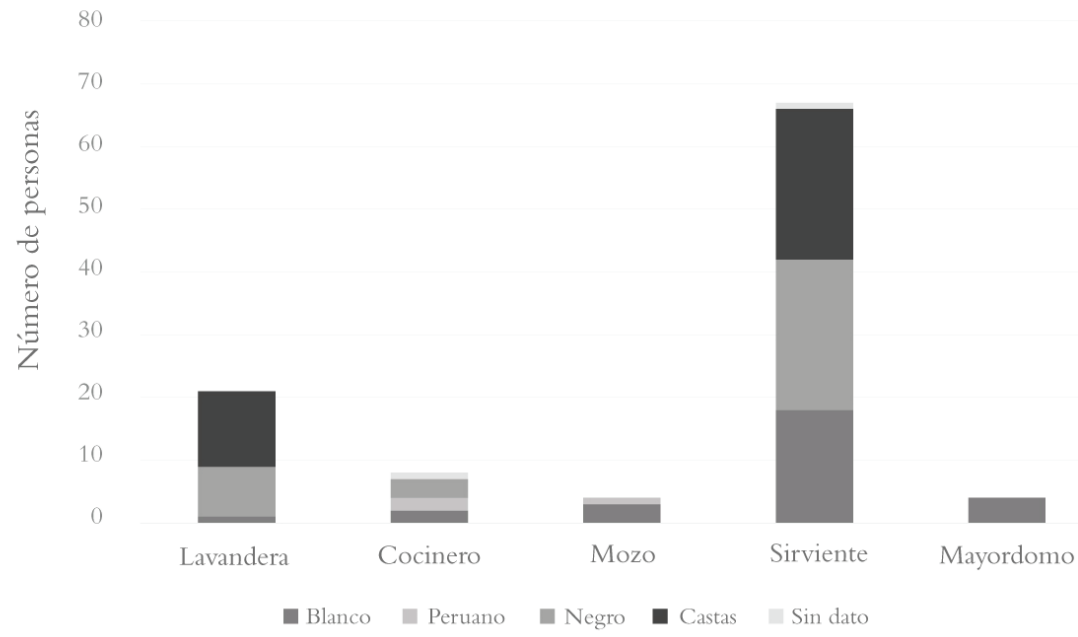

Fuente: AHML, Gobiernos Distritales 1812-1839, Padrón de población de Lima, 1824.

Tabla 11. Porcentaje de calidades según oficio. Barrios 1 y 3, 1824

\begin{tabular}{|l|c|c|c|c|c|}
\hline \multicolumn{1}{|c|}{ Oficios } & Blanco/a & Peruano/a & Moreno/a & Castas & Sin dato \\
\hline Comerciantes & 97.8 & - & - & 2.2 & - \\
\hline Artesanos & 46.5 & 13.4 & 1.7 & 33.1 & 5.2 \\
\hline Tenderos & 41.4 & 21.4 & 10 & 24.3 & 2.9 \\
\hline Domésticos & 26.9 & 2.9 & 33.7 & 34.6 & 1.9 \\
\hline Militares & 82.1 & 3.6 & 3.6 & 10.7 & - \\
\hline Profesionales & 88.9 & 3.7 & 0 & 0 & 7.4 \\
\hline Empleados/as & 72.7 & 0 & 0 & 18.2 & 9.1 \\
\hline Artistas & 100 & - & - & - & - \\
\hline Otros & 42.1 & 10.5 & 15.8 & 15.8 & 15.8 \\
\hline $\begin{array}{l}\text { Menores de 14 } \\
\text { años }\end{array}$ & 33.3 & 14.3 & 19 & 33.3 & - \\
\hline Fuente: AHML, Lima, Gobiernos Distritales 1812-1839, Padrón de población de Lima, 1824. & & & \\
\hline
\end{tabular}




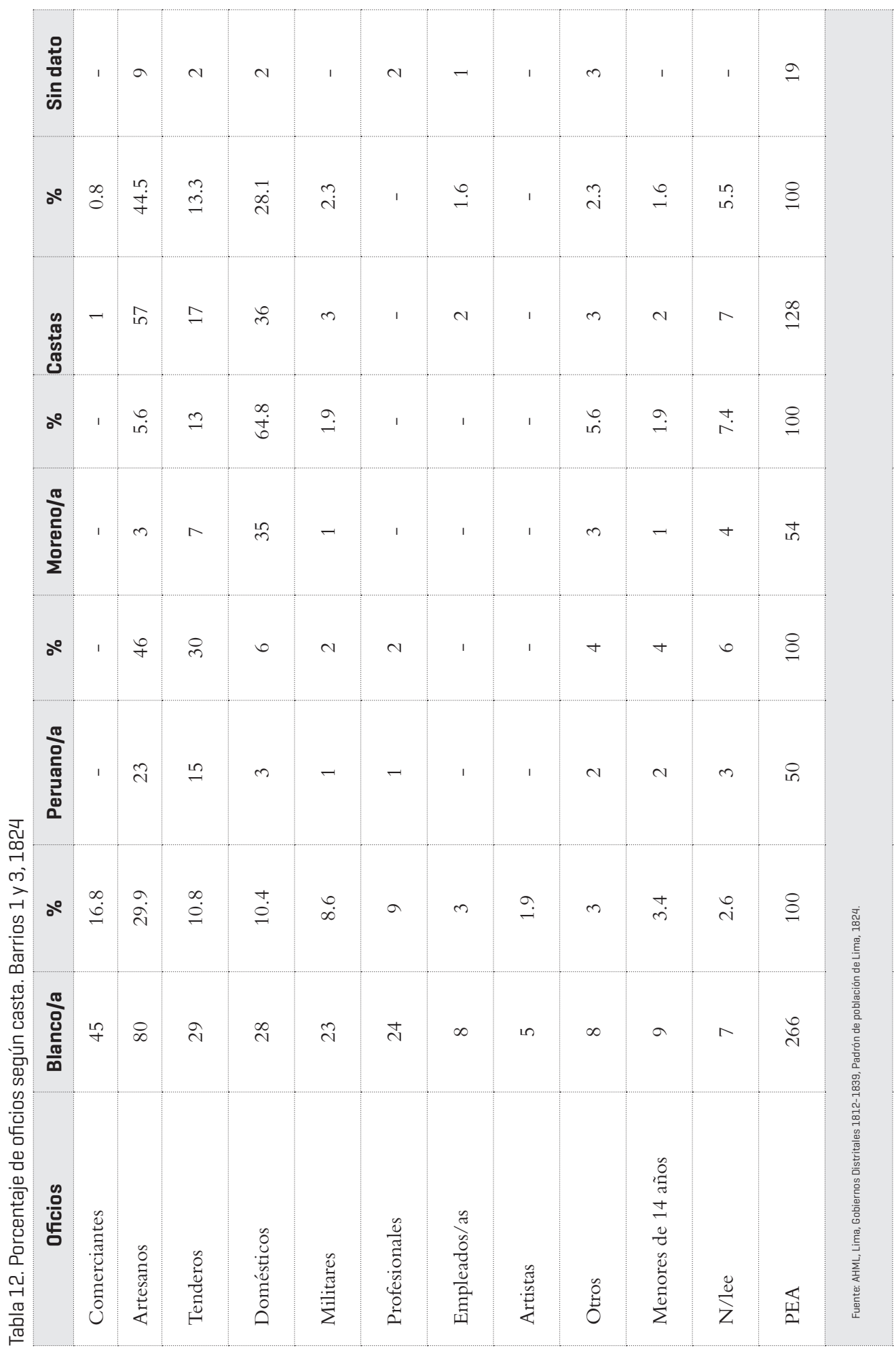


Tabla 13. Porcentaje de calidades según tipo de vivienda. Barrios 1 y 3, 1824

\begin{tabular}{|l|c|c|c|c|c|}
\hline \multicolumn{1}{|c|}{ Tipo de habitación } & Blanco/a & Peruano/a & Negro/a & Castas & Sin datos \\
\hline Casa & 66.8 & 3.4 & 6 & 17.6 & 6.2 \\
\hline Casita & 70.8 & 6.9 & 8.3 & 13.9 & - \\
\hline Cochera & - & 75 & 6.3 & 18.8 & - \\
\hline Altos & 61.1 & 1.9 & 7.4 & 24.1 & 5.6 \\
\hline Callejón & 45.3 & 6.3 & 4.2 & 42.1 & 2.1 \\
\hline $\begin{array}{l}\text { Establecimientos } \\
\text { comerciales }\end{array}$ & 49.4 & 15.6 & 7.4 & 18.9 & 8.6 \\
\hline No confirmado & 35.3 & 5.9 & 23.5 & 29.4 & 5.9 \\
\hline
\end{tabular}

Figura 10. Estructura de tipos de vivienda según casta. Barrios 1 y 3, 1824

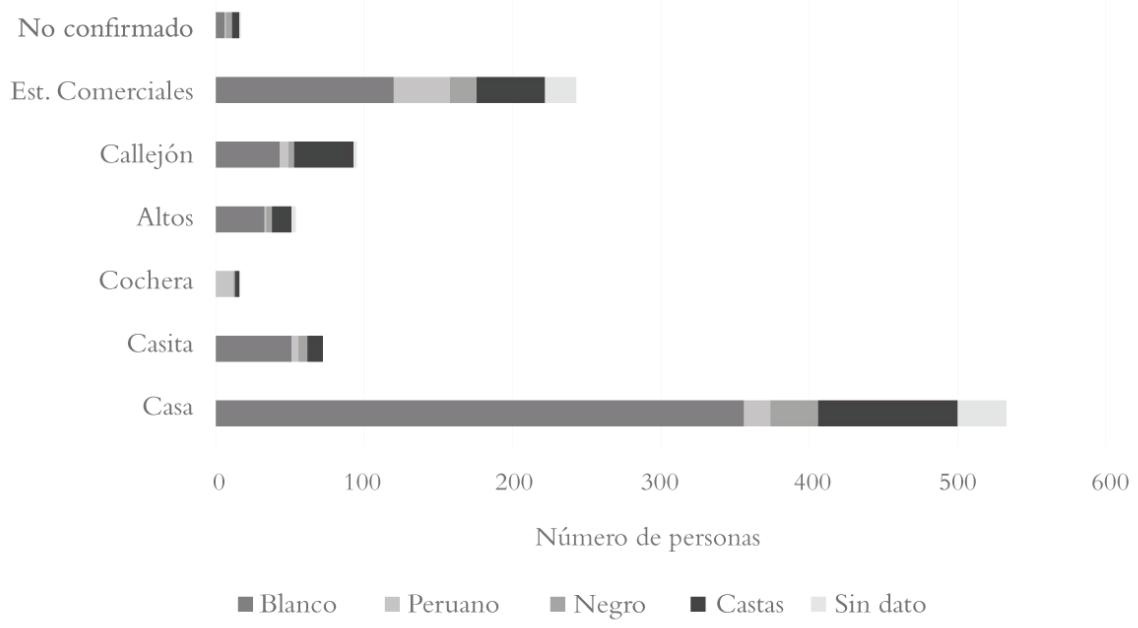

Fuente: AHML, Gobiernos Distritales 1812-1839, Padrón de población de Lima, 1824. 
los blancos, presumiblemente de entre los más pobres, como los cajoneros y los mercachifles.

Si la estructura de ocupación por casta nos ayuda a dilucidar las formas de la jerarquía social, el tipo de residencia que esta población habitaba (y, por tanto, se podía permitir) lo esclarece aún más.Así, se observa cómo la población blanca era mayoría en las casas y en las casitas, mientras que los no blancos fueron el grupo más grande dentro de los callejones. En los altos, que era otro grupo de habitaciones populares, fueron los blancos los más numerosos, lo cual puede explicarse porque en su mayoría estos estaban anexados a las casas, por lo que las familias blancas las preferían por estar rodeadas de "gente decente", a pesar de haber perdido capacidad económica. ${ }^{39}$ Los establecimientos comerciales eran espacios en los que ambos grupos se encontraron con un peso relativo similar ( $49.4 \%$ blancos y $50.6 \%$ no blancos), lo que habla de la necesidad que tenían de residir en su lugar de trabajo un buen número de tenderos no blancos, así como los cafeteros o pulperos. Finalmente, solo indígenas y afrodescendientes (moreno/as y castas) vivían en las pocas cocheras consignadas como habitaciones.

Mención aparte merece el hecho de que la mayoría de población afrodescendiente del barrio tercero vivía en las casas de familia, ya sea en condición de arrendadores o de sirvientes domésticos. En efecto, todo parece indicar la presencia de una importante población afrodescendiente, en partes iguales entre hombres y mujeres, quienes viven en su mayoría en condiciones de servidumbre en las casas de familia dentro del barrio 3 (en el que ese número asciende a 50\% negros y 56.3\% las castas) (Tabla 14).

La cuestión parece ser ya repetitiva. En realidad, la población registrada como servidumbre doméstica residía en tan solo 30 unidades habitacionales: 24 casas, cuatro casitas, dos altos y una panadería; a razón de 3.2 sirvientes por cada residencia. Así, de solo un pequeño número de familias del barrio, tres podían mantener sirvientes en sus casas; sin embargo, eran capaces en conjunto de solventar los gastos económicos de un porcentaje importante de la población de su barrio (76 personas, equivalente al 10.5\% del tercer barrio, sin contar a los "niños chiquitos"). ${ }^{40}$

Finalmente, un último dato nos puede ayudar a extraer mejores conclusiones del cuerpo documental estudiado: la estructura de la clasificación "don/ doña", la cual, a fines de la colonia, más que representar la ascendencia hidalga de una persona, reflejaba su estatus como "gente decente". En ese aspecto, los números muestran una clara tendencia: quienes llevaban el título de don o doña eran en un $80.9 \%$ personas blancas, mientras que solo $20.1 \%$ corresponden a otros grupos sociorraciales. En el sentido inverso, también se demuestra que, si bien la mayoría de los "dones" eran blancos, no todos los blancos ostentaban este calificativo, pues, de los 609 registrados como tales, solo el 75.7\% tenía ese rótulo. Algo parecido pasaba con los grupos no blancos, quienes, aunque en su mayoría no eran "dones", al menos $12.8 \%$ de ellos entraban en esa categoría (Tabla 15).

39. Zegarra Flórez 194.

40. La panadería sirvió como lugar de trabajo para las personas esclavizadas a fines del periodo colonial. En ese sentido, este dato mantiene la tendencia de los antiguos esclavos de mantener sus trabajos como sirvientes libres. 
Tabla 14. Porcentaje de tipo de vivienda según calidades. Barrios 1 y 3, 1824

\begin{tabular}{|c|c|c|c|c|c|c|c|c|}
\hline \multirow{2}{*}{$\begin{array}{c}\text { Tipo de } \\
\text { habitación }\end{array}$} & \multicolumn{2}{|c|}{ Blanco/a } & \multicolumn{2}{|c|}{ Peruano/a } & \multicolumn{2}{|c|}{ Negro/a } & \multicolumn{2}{|c|}{ Castas } \\
\hline & B1 & В3 & B1 & B3 & B1 & B3 & B1 & B3 \\
\hline Casa & 54.1 & 60.9 & 27.3 & 21.4 & 27.3 & 50 & 29.3 & 56.3 \\
\hline Casita & 4.6 & 10.5 & - & 7.1 & - & 10.3 & - & 8.4 \\
\hline Cochera & - & - & - & 17.1 & - & 1.7 & 3.3 & - \\
\hline Altos & 6.9 & 4.6 & - & 1.4 & - & 6.9 & 5.4 & 6.7 \\
\hline Callejón & 16.1 & 2 & 18.2 & 5.7 & 18.2 & 3.4 & 38 & 4.2 \\
\hline $\begin{array}{l}\text { Establecimientos } \\
\text { comerciales }\end{array}$ & 18.3 & 20.5 & 54.5 & 45.7 & 36.4 & 24.1 & 23.9 & 20.2 \\
\hline No confirmado & - & 1.5 & - & 1.4 & 18.2 & 3.4 & - & 4.2 \\
\hline Artistas & 5 & 1.9 & - & - & - & - & - & \\
\hline
\end{tabular}

Tabla 15. Número de "dones" por barrio. Barrios 1 y 3, 1824

\begin{tabular}{|l|c|c|c|c|}
\hline \multicolumn{1}{|c|}{ Casta } & B1 & B3 & Total & Porcentaje \\
\hline Blanco/a & 200 & 261 & 461 & 80.9 \\
\hline Peruano/a & 4 & 20 & 24 & 4.2 \\
\hline Negro/a & 1 & 5 & 6 & 1.1 \\
\hline Castas & 19 & 24 & 43 & 7.5 \\
\hline Sin datos & 35 & 1 & 36 & 6.3 \\
\hline Total & 259 & 311 & 570 & 100 \\
\hline
\end{tabular}




\section{Conclusiones}

El presente artículo permite realizar un acercamiento microscópico a la estructura socioeconómica de la ciudad de Lima en 1824. En ese sentido, ayuda a comprobar varias hipótesis y rebatir algunos supuestos sobre la ciudad en un momento de cambio profundo y un contexto de gran convulsión social por la preparación para la guerra y los continuos conflictos bélicos. A partir de este acercamiento, fue posible observar que la zona central del distrito 1 (los dos barrios de este estudio) era un área tradicional de poder en la ciudad, pero que había perdido importancia debido a la coyuntura bélica y de dislocación social en que varios de sus nombres principales habían tenido que dejar la ciudad o se habían unido a las luchas militares por uno u otro bando. En estos barrios se puede observar una estructura de edades y sexo propia de una ciudad en crecimiento del periodo preindustrial, en la que existe una mayoría de población joven y una baja representación de adultos mayores, a pesar del problema del subregistro infantil que se encontró. Al mismo tiempo, un claro desbalance de los sexos en las edades de trabajo indicó no solo la movilización de un porcentaje importante de los hombres, sino también una tasa importante de subregistro.

También fue posible caracterizar el espacio como uno dedicado a fines comerciales públicos, con una buena tasa de artesanos, tenderos y comerciantes, quienes se hospedaban principalmente en las casas de familia que les daban alojamiento. Asimismo, mientras el barrio 1 tenía una tradición de poder y lujo más antigua, reflejada en el precio de la vara cuadrada y el alto número de casas fastuosas, las circunstancias de la guerra habían movilizado a su personal doméstico y a sus jefes de familia, lo que lo dejó seriamente empobrecido y subrepresentado, incluso a nivel de vecinos mayores de edad. Así, mientras sus grandes casas se despoblaron, sus callejones se llenaron de personas. En contraste, el barrio 3 se perfiló como el de mayor población, con una capacidad para mantener a quienes prestaban servicios domésticos, así como a un número menor de casas grandes, pero en mejores condiciones. En su conjunto, estos barrios expresarían tanto la unidad de un espacio de prestigio dentro del entramado urbano, signado en su relativo privilegio por la presencia de una pileta pública y la cercanía de la Plaza Mayor, como la heterogeneidad social propia de la ciudad y sus fenómenos urbanos particulares.

Finalmente, la riqueza intrínseca de la variable "casta" permitió observar también otros fenómenos. En particular, la estrecha relación existente entre la jerarquía social y la consideración racial a inicios de la República. Aunque, por el contexto en que fue confeccionado, no se hallaron esclavos mayores de edad en el padrón, la impronta de esta realidad se descubre por el alto número de sirvientes afrodescendientes. Asimismo, algunas ocupaciones, sobre todo profesionales y mercantiles, eran muy pobremente representadas entre las castas. Como demuestra el número de "dones", el ser "decente" tenía mucho que ver con cómo te percibían racialmente; sin embargo, como el mismo padrón demostró, la procedencia no determinaba completamente la vida a inicios del siglo XIX, pues un grupo importante de 
los "no blancos" lograba conseguir ocupaciones rentables en el artesanado, como militares o empleados, y vivir en casitas, símbolo de la prosperidad relativa de este estrato.

De esta forma, este trabajo permite explicar el perfil de cada uno de los barrios analizados y, mediante este método, aportar al estudio no solo de la caracterización sociodemográfica de la ciudad de Lima en un periodo convulso y de continua movilidad como el estudiado, sino de la jerarquización socioespacial en este escenario de cambio. Así, la baja representatividad del estudio barrial no se convierte en impedimento para dar caracterizaciones respecto de la zona que se encuentra representada, y es menester llevar este tipo de trabajos a un estudio más amplio tanto a nivel diacrónico (en el tiempo) como sincrónico (en el espacio). De la misma manera, este artículo es una muestra de lo que permite el estudio de la información demográfica fragmentaria que proliferó durante la República temprana y que no se ha estudiado a profundidad, al olvidar la importancia que pueden tener para la historia social, demográfica y de la familia.

\section{Fuentes}

\section{Manuscritas}

Archivo Histórico Municipal de Lima, Lima (AHML)

Gobiernos Distritales

Libros de Cabildo

\section{Impresas}

Atanasio Fuentes, Manuel. Estadística general de Lima. Lima:Tip. Nacional de M. N. Corpancho, 1868.

Córdova y Urrutia, José María. Estadística histórica, geográfica, industrial y comercial de los pueblos que componen las provincias del departamento de Lima. Lima: Imprenta de Instrucción Primaria, 1839.

Gamio Palacio, Fernando. Plano de la Ciudad de Lima en 1821. Lima: Concejo Provincial de Lima, 1944.

\section{Periódicos}

El Investigador del Perú (Lima) 1813.

\section{Bibliografía}

Araya Espinoza, Alejandra. "Registrar a la plebe o el color de las castas: 'calidad', 'clase' y 'casta' en la Matrícula de Alday (Chile, siglo XVIII)”. América colonial. Denominaciones, clasificaciones e identidades, Chile, siglo XVIII. Eds. 
Alejandra Araya Espinoza y JaimeValenzuela Márquez. Santiago de Chile: RIL Editores / Pontificia Universidad Católica de Chile / Universidad de Chile, 2010.

Arnold, Linda. "Sobre la deducción de evidencia: estratificación en un barrio de la ciudad de México, 1777-1793”. Estudios de Historia Novohispana 15 (1995): 87-111.

Barcia Zequeira, María del Carmen. "Una mirada social a las familias. Su reflejo en censos y padrones (1870-1919)". Revista de Indias 60.219 (2000): 453475.

Basadre,Jorge. Historia de la República del Perú (1822-1933). Tomo 1. Lima:Editorial Universitaria, 1983.

Bromley, Juan. Las viejas calles de Lima. Lima: Municipalidad Metropolitana de Lima / Gerencia de Educación, Cultura y Deportes / Edilibros, 2005.

Cosamalón Aguilar, Jesús. El juego de las apariencias. La alquimia de los mestizajes y las jerarquías sociales en Lima, siglo XIX. Lima / Ciudad de México:: Instituto de Estudios Peruanos / El Colegio de México, 2017.

Indios detrás de la muralla. Matrimonios indígenas y convivencia inter-racial en Santa Ana (Lima, 1795-1820). Lima: Pontificia Universidad Católica del Perú, 1999.

De Haro Romero, Dionisio. "Para pagar la guerra: el Padrón de Contribuyentes de Lima (1821) y la política liberal del virrey La Serna”. Revista de Indias 79.275 (2019): 197-233. Doi: 10.3989/revindias.2019.007.

Estenssoro Fuchs, José Carlos y otros. “Los colores de la plebe: razón y mestizaje en el Perú colonial”. Los cuadros del mestizaje del virrey Amat. La representación etnográfica en el Perú colonial. Ed. Natalia Majluf. Lima: Museo de Arte de Lima, 1999.

Flores Galindo, Alberto. Aristocracia y plebe, Lima 1760-1830: estructura de clases y sociedad colonial. Lima: Mosca Azul Editores, 1984.

Gootenberg, Paul. Población y etnicidad en el Perú republicano (siglo XIX): algunas revisiones. Lima: Instituto de Estudios Peruanos, 1995.

Hampe Martínez, Teodoro y José F. Gálvez Montero. "De la intendencia al departamento (1810-1830): los cambios en la administración pública regional del Perú". Revista de Historia de América 125 (1999): 105-132.

Livi-Bacci, Massimo. "The Depopulation of Upper Amazonia in Colonial Times". Revista de Indias 76.267 (2016): 419-448. Doi: 10.3989/ revindias.2016.013.

Obara-Saeki, Tadashi. Ladinización sin mestizaje. Historia demográfica del área chiapaneca, 1748-1813. Chiapas: Consejo Estatal para las Culturas y Artes de Chiapas, 2010.

Parker, David S. "Los pobres de clase media: estilo de vida, consumo e identidad en una ciudad tradicional". Mundos Interiores: Lima 1850-1950. Eds. Aldo Panfichi H. y Felipe Portocarrero S. Lima: Universidad del Pacífico, 1995. 
Peloso, Vincent y José Ragas. "Estadística y sociedad en el Perú poscolonial: el desconocido censo de Lima de 1860”. Histórica 25.2 (2001): 275-293.

Ramón Joffré, Gabriel. "Autoridades subalternas y proyecto borbónico (17461821) : el plano de las aguas urbanas de Lima”. El ocaso del antiguo régimen en los imperios ibéricos. Coords. Scarlett O’Phelan Godoy y Margarita Eva Rodríguez García. Lima: Pontificia Universidad Católica del Perú / CHAMCentro de Humanidades, Faculdade de Ciências Sociais e Humanas, Universidade NOVA de Lisboa / Universidade dos Açores, 2017. . "Ilustrar la urbe: planos de la Lima borbónica". Illapa 7 (2010): 63-79. Doi: 10.31381/illapa.v0i7.1045.

. La muralla y los callejones: intervención urbana y proyecto político en Lima durante la segunda mitad del siglo XIX. Lima: Seminario Interdisciplinario de Estudios Andinos / Comisión de Promoción del Perú, 1999.

Stolcke, Verena. Racismo y sexualidad en la Cuba colonial. Madrid: Alianza Editorial, 1992.

Yvinec, Maud. "Reinventar el indio después de la Independencia: las representaciones del indígena en el Perú decimonónico (1821-1879)". Bulletin de l'Institut Français d'Études Andines 42.2 (2013): 287-293. Doi: 10.4000/ bifea. 4087.

Zegarra Flórez, Margarita. "El honesto velo de nuestro sexo. Sociabilidad y género en mujeres de sectores populares, en la Lima del 800”. Mujeres y Género en la Historia del Perú. Ed. Margarita Zegarra Flórez. Lima: CENDOC Mujer, 1999. 